\title{
CORRECTION
}

\section{Correction to: Sorption of radioactive cobalt onto nano calcium silicate/CuO composite modified by humic acid}

\author{
H. S. Hassan ${ }^{1}$ - D. M. Imam ${ }^{1}$ - S. H. Kenawy ${ }^{2}$ - G. T. El-Bassyouni ${ }^{2}$ - E. M. A. Hamzawy ${ }^{3}$
}

Published online: 11 July 2019

(c) Akadémiai Kiadó, Budapest, Hungary 2019

\section{Correction to: \\ Journal of Radioanalytical and Nuclear Chemistry https://doi.org/10.1007/s10967-019-06599-2}

In the original publication of the article, Figs. 8, 9 and 10 were published incorrectly as linear regression. However, the equations and the discussions are expressed for non-linear regression in the article. The correct versions of Figs. 8, 9 and 10 with non-linear forms are provided in this correction.
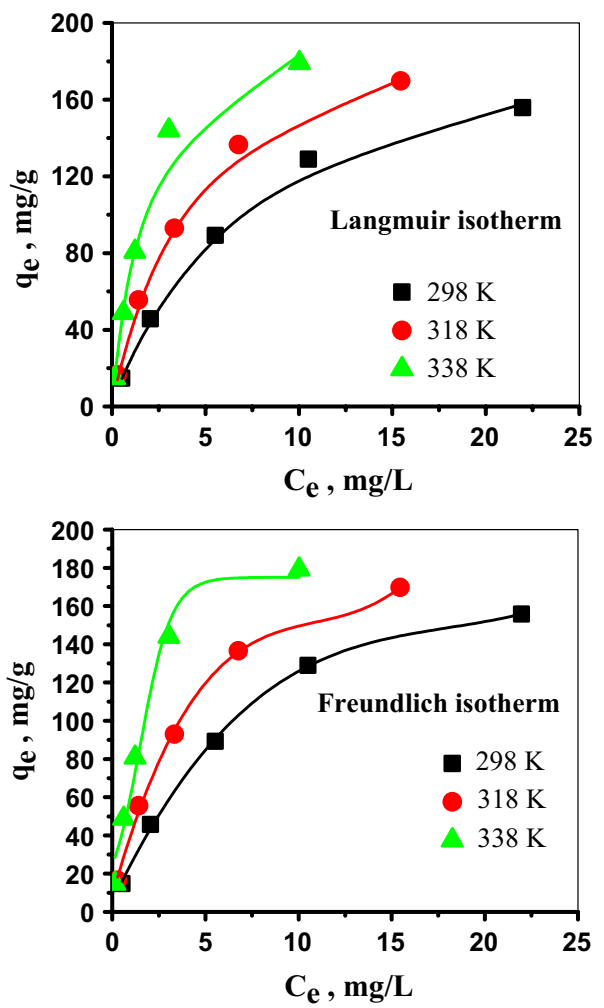

Fig. 8 Langmuir and Freundlich isotherms for ${ }^{60} \mathrm{Co}$ radionuclide sorption onto prepared $\mathrm{CS}-\mathrm{CuO}$ with humic acid
The original article can be found online at https://doi.org/10.1007/ s10967-019-06599-2.

S. H. Kenawy

ksayed6631@gmail.com

1 Hot Laboratories and Waste Management Center, Atomic Energy Authority, Cairo 13759, Egypt

2 Refractories, Ceramics and Building Materials Department, National Research Centre, Cairo 12622, Egypt

3 Glass Research Department, National Research Centre, Cairo 12622, Egypt 


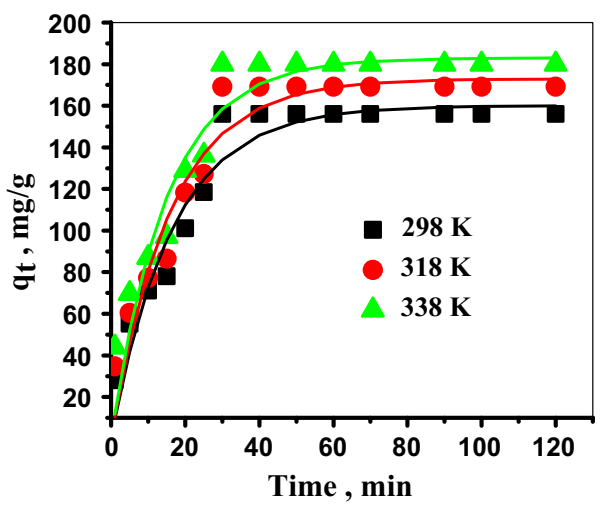

Fig. 9 Pseudo-first-order kinetic model for ${ }^{60} \mathrm{Co}$ radionuclide sorption onto prepared $\mathrm{CS}-\mathrm{CuO}$ with humic acid

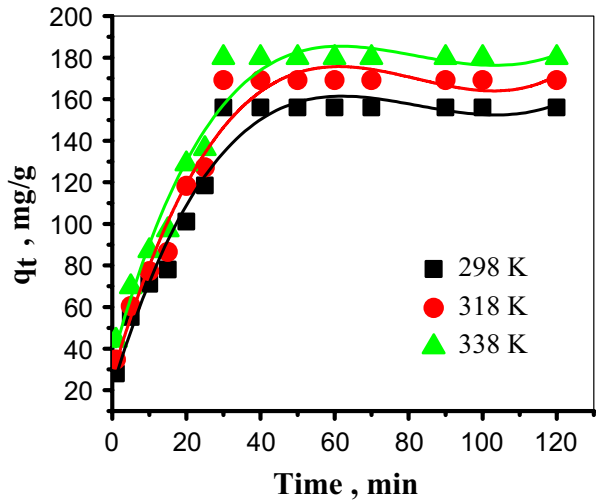

Fig. 10 Pseudo-second-order kinetic model for ${ }^{60} \mathrm{Co}$ radionuclide sorption onto prepared $\mathrm{CS}-\mathrm{CuO}$ with humic acid

Publisher's Note Springer Nature remains neutral with regard to jurisdictional claims in published maps and institutional affiliations. 